\title{
Cognition and Practice about Curriculum Teaching Design
}

\author{
Haiyu $\mathrm{Li}^{1}$, Chunhua Zhang ${ }^{1}$, Xiaohua Song ${ }^{1}$, Nan Zheng ${ }^{2}$ \\ 1.Department of Computer Aviation University of Air Force Changchun Jilin ,China \\ 2.Special Professional Department Aviation University of Air Force Changchun Jilin ,China \\ haiyu9871@tom.com
}

Keywords: curriculum teaching design, essence and connotation, basic demands, main contents

\begin{abstract}
Design is a job that must be finished before any complex task and activity, and curriculum teaching is also not to the exception. Before we carry out curriculum teaching, we must do well in curriculum teaching design. This article takes improving curriculum teaching quality as traction, takes systematic theories and modern education and teaching theory as reliance and states about essence, connotation, basic demands and main contents of curriculum teaching design.
\end{abstract}

\section{INTRODUCTION}

Curriculum teaching is a system which depends on organic combination of teaching contents, students, teachers and teaching conditions to finish curriculum teaching function and achieve curriculum teaching target. We must follow systematic law and modern education and teaching law to make optimized design toward curriculum teaching. So we can see curriculum teaching design is an important expression of following objective law, an important precondition of achieving curriculum teaching target and an important guaranty of improving curriculum teaching quality. To correctly recognize curriculum teaching design is mental foundation of optimizing curriculum teaching design; optimizing curriculum teaching design is value pursuit of improving teaching quality and doing well in curriculum teaching design is a strategic task in curriculum teaching. We must deepen rational cognition and practical research toward curriculum teaching design, improve level of curriculum teaching design and guarantee curriculum teaching quality.

\section{ESSENCE AND CONNOTATION OF CURRICULUM TEACHING DESIGN}

Curriculum teaching design owns objective essential attribute. Only if we correctly recognize its essence and connotation and enhance function and role can we do well in curriculum teaching design.

\section{A. Design}

"Set" in design has the original meaning of "trying to set up" and "plan" in design has the original meaning of "making strategy", so the original meaning of design is planning by setting up in advance. When we link original meaning of design with design task to make comprehensive understanding, design means to depend on target and demand of the task, to set up working scheme or plan in advance and draw necessary pattern. We should pay attention to what is design, what's more, we should pay attention to how to do well in design. As for design in any field, we should follow common law as needed in design itself--that is systematic law besides following particular law of design in this field. We should treat design object as a system which can exchange energy or information and can make effective control. We should make use of systematic science and design an integrity of organic combination, reasonable structure, powerful function and effective control according to systematic function, target and demand.

\section{B. Curriculum teaching design}

Curriculum teaching design is a particular design facing curriculum teaching system. On one hand, we should follow systematic law; on the other, we should follow modern education and teaching law. Because of complex and contradictory features of two kinds of people in curriculum teaching system, and essential change of modern teaching concept, talent concept and quality concept with many complex factors which can influence systematic function and operation, therefore, curriculum teaching design is a systematic, complex and innovative job. Now there is no united definition toward curriculum teaching design, thus it reflects complex, multiple and interactive features of 
curriculum teaching design. The author thinks that no matter how complex the problems of curriculum teaching design are, we can always reveal its essence and connotation from objective law.

Through analysis toward design and curriculum teaching system, we can essentially state curriculum teaching design as that curriculum teaching design takes curriculum teaching target and demand as reference. It uses systematic theories and modern education and teaching theories. On the base of making integral analytic design toward preliminary condition of curriculum teaching system, it forms a curriculum teaching integral scheme or plan with organic combination and draws necessary pattern upon overall planning and optimized structure of teaching elements in stationary state and upon scientific decision-making of teaching process, teaching activity and judge and control in running state.

\section{BASIC DEMANDS OF CURRICULUM TEACHING DESIGN}

\section{A. To stand out normative feature of curriculum teaching design}

We should take curriculum standard as reference, and stand out normative feature of curriculum teaching design. When we make teaching design, we should comprehensively consider about functions of various factors and make them exert integral effect. Each step should have its certain function, and will produce important influence toward learning process and result. Therefore, we can't neglect design of each step, instead, we should enable it to serve for really solving teaching problems. Therefore, we should seriously analyze the detailed demands of curriculum standard toward all aspects in curriculum teaching. We should implement them into curriculum teaching design, achieve the demand of curriculum standard and further make fine analysis, research and curriculum teaching design under the specification of curriculum standard.

\section{B. To stand out pertinence of curriculum teaching design}

We should adapt to features of teaching object and stand out pertinence of curriculum teaching design. First, we should make normal and particular analysis toward education type, intelligent and non-intelligent quality, knowledge level, ability and quality of teaching object, make scientific orientation toward teaching start and teaching strategy to make them accord with features of teaching object and guarantee that their learning need and motivation, knowledge experience and intelligence and skill, cognition strategy and learning pattern well match with curriculum learning. Next, we should unite dynamic factor, intelligent factor and strategic factor, develop students' intelligence, interest and sense of learning efficacy in the activities of enhancing cognition and make learning process become the process for students to obtain overall and harmonious development. Especially we should satisfy students' demand of self-study and fully embody individual cultivation toward students.

\section{To stand out scientific feature of curriculum teaching design}

We should follow systematic law and stand out scientific feature of curriculum teaching design. We should adopt systematic theories to make analysis and design; we should plan curriculum teaching elements as a whole; we should optimize structure, plan running and form an organic integrity which can achieve teaching target with optimized element distribution, scientific and reasonable structure and orderly and effective operation. We should do overall design on the base of preliminary condition analysis; we should do teaching element design in stationary state; we should also do design in teaching process, teaching activity and judge and control in running state.

\section{To stand out innovative feature of curriculum teaching design}

When we pay attention to normalization of teaching design, we teachers should fully exert creativity. In teaching design process, we should insist in flexibly using teaching design process pattern and choosing suitable teaching design process as reference of teaching design according to the demand of actual teaching.

\section{MAIN CONTENTS OF CURRICULUM TEACHING DESIGN}

Main contents of curriculum teaching design include overall design on the base of comprehensive analysis of the preliminary condition, teaching element design in stationary state and teaching implementation design in running state. 


\section{A. Overall design for teaching}

Overall design is top design to confirm basic thought in curriculum teaching. We should make analysis toward curriculum teaching demand according to target and demand in curriculum standard; we should make analysis toward current condition of curriculum teaching according to objective condition of preliminary condition of curriculum teaching; we should find out contradiction and distance between current condition and demand and confirm basic thought in curriculum teaching. Analysis toward teaching demand includes analysis toward knowledge cultivation, ability cultivation and quality cultivation demand. We should scientifically locate overall target of curriculum teaching through comprehensive analysis toward knowledge cultivation, ability cultivation and quality cultivation demand. Analysis toward current condition of teaching refers to comprehensive analysis toward teaching object, teacher, teaching content, current situation of teaching condition and environment disturbing condition. We should find out favorable and unfavorable factors of implementing curriculum teaching and scientifically locate logic starting point of implementing curriculum teaching. As for basic thought of teaching, we should find out logic master line of curriculum teaching according to comprehensive gradient between demand and current condition, and put forward macro-guidance, macro-measures, macro-routine and macro-demands for curriculum teaching surrounding this master line.

\section{B. Teaching element design}

Teaching element design refers to optimized design toward 4 elements in system like teaching content, students, teachers and teaching condition. It includes reconstruction of teaching contents, teaching method choice and teaching condition setting.

\section{1) Reconstruction of teaching contents}

System theory is an important theoretical evidence of reconstruction of teaching contents. System theory tells us that function of a system not only depends on elements of its content, but also depends on structure among all elements. System with a good structure tends to produce the effect of "integrity is larger than the sum of its parts", therefore, we should do the following two points:

First, we should prepare teaching material with creativity. Teaching material is major evidence for teaching. But it doesn't mean that we must follow the order of material arrangement to give lessons in teaching, instead, we should use creative eyesight to view the teaching material and creatively use it, but we can't be slave for the teaching material. We should do well in "holding two passes", "having three thorough grasps" and "making three transforms". "Two passes" refer to student pass and teaching material pass. Firstly, we should know about students' level of recognition, cognition mentality, learning attitude and interest. Next, we should do well in the teaching material pass. The following are about three grasps. Firstly, we should have a through grasp of position, function, main clue and vertical and horizontal links of teaching contents in the material, we should master integral structure of knowledge;secondly, we should have a through grasp of compiling purpose and knowledge system of the material, make reconstruction and proceeding, change present teaching design contents and change inherited contents into creative contents. For this, we should master analysis in 4 points, and they are important points, difficult points, training points for ability and thinking methods and cultivation points for ideological eduction and individuality. We should dig out creative elements contained by the material itself and cultivate students' creative thinking and quality; thirdly, we should have a through grasp of education element of the teaching material and master three-dimensional target in teaching, and they are knowledge target, ability target and emotion and moral education target. Third, we should solve principal contradiction in class between students and teaching material from the angle of optimizing teaching process, and enable students to realize three transforms through having classes. They are transform of recognition process which makes students to change from "not knowing" to "knowing", from "knowing little to knowing much"; transform of emotion process which guides students to change from disliking study to liking study, willing to study and able to study; transform of ability process which guides students to form skills in actual use and change from "not using" to "able to use" and "flexibly using".

Second, Networking construction of knowledge structure. Knowledge in human brain is not simply overlaid or piled, but is stocked with certain special structure. Students' cognition is not finished once but realized in constant and repeated circulation. Mastering fundamental structure of subject is helpful for positive migration of study, helpful for deep understanding and overall 
mastering toward subject and helpful for memorizing knowledge on the base of understanding. Therefore, in teaching contact, we needn't conform strict linear type level, nor do we need paying attention to all. Knowledge is made up of network structure surrounding critical concept. So long as we seize the backbone of network, our study can start from any part of network. We should follow the principle of "delicate teaching and more practice" and leave students more thinking space. Thus students will have more energy in self-study, will have more time for self-exploration and student's recognition would rise in a spiral in constant circulation. Practice proves that through reconstruction toward teaching content, students learn smoothly, teachers get easy to give lessons, knowledge is consolidated in circulation, teachers could solve problems in progress and offer time for students to comprehensively use knowledge.

All in all, in the process of teaching content reconstruction, whether teachers can change difficult contents into easy ones and make boring contents and problems become attractive are challenge for teachers' teaching intelligence and ability and become one of important steps to decide teaching quality in class.

2) Teaching method choice

Usually we think that teaching method is made to achieve teaching purpose, to realize teaching contents and to use teaching approach. It is activity pattern composed by one whole set of patterns with interactive functions between teachers and students guided by teaching principle. Japanese scholar Sato Masao stated essence of teaching method in his Teaching Principle ${ }^{\left[{ }_{1}\right]}$ that teaching methodology was the most important teaching approach to guide and adjust teaching process. It refers to principled steps that must be followed by teachers and students in teaching aiming to realize target planned by the course (subject course) and to teach certain teaching contents (teaching content and material). Therefore, we can comprehend teaching method as activity pattern of mutual activity of teaching and study adopted by teachers and students in teaching process for finishing teaching purpose and task. It both includes patterns and methods of teaching activity by teachers and includes patterns and methods of learning by students under guidance of teachers, so it is unity of teaching methods and learning methods. ${ }^{[4]}$

In the process of choosing teaching method, we should make comprehensive selection toward learning method and teaching method according to features of curriculum, object and teachers. We should fully embody self activity type and self development type teaching which take learning as main part and teaching as dominance. We should be good at choosing to use modern teaching methods such as concept network type, inspiration type, discussion type, exploration type, case type, situation type and circumstance type, etc.

The purpose for teachers to choose teaching method is to make effective use in actual teaching activity. In order to solve this problem, we must notice the following several aspects ${ }^{[4]}$ : firstly, we should comprehensively use various teaching methods. Overall achievement of teaching target can't be finished only with single teaching method. We should make optimized conformation and comprehensive use toward the chosen teaching methods, and exert the comprehensive and integral function of different teaching methods to obtain good teaching effect and improve teaching quality. Secondly, we should pay attention to students' participation and make flexible use. The application process of teaching methods can't only be teachers' performance process. Actually it is the process for common participation and mutual cooperation between teachers and students. Therefore, when teachers use teaching methods, they should fully consider about students' exerting of main part function to make students take active part in teaching activity and form lively teaching atmosphere. Besides, teachers should also pay attention to gusty elements in teaching activity and make flexible use of teaching method. Thirdly, we should insist on the guidance thought of inspiration-type teaching. No matter which teaching method we adopt, we should carry out inspiration-type teaching thought in actual use. Inspiration-type teaching is not a concrete teaching method but a guidance thought of teaching method. It demands teachers to start from actual condition of students, treat students as main part for study, make use of various patterns to stimulate students' enthusiasm, guide students to master knowledge, form skill, develop ability through their own active learning activities and promote students to obtain individual and healthy development. Therefore, in application process of various teaching methods, carrying out inspiration-type teaching can fully exert functions of various teaching methods.

3) Teaching condition setting 
Overall demands of course upon teaching condition setting include demands in teaching equipment and facility, demands in teaching material selection, demands in network resource and demands in book material, etc. Demands in equipment and facility are mainly demands toward teaching site like classroom, professional classroom and laboratory, etc and demands in equipment and furnishment. Demands in teaching material selection are mainly demands toward selection of major teaching material, supplementary teaching material and reference material. Demands in network resource are mainly demands toward application of Internet and campus web resource. Demands in book materials are mainly demands toward journal, magazine, image and chart material, audio material and teaching case material.

\section{Teaching implementation desig}

Teaching implementation design is concrete arrangement toward teaching process, unit teaching arrangement, teaching judge and control and course examination in running state.

Teaching process arrangement means to optimize reconstructed fundamental unit and structure according to teaching contents, confirm about teaching process and form a scientific and rational teaching schedule. Basic elements in teaching schedule include course order, course name, nature(speaking, experiment, and practice), main contents, level demand( to know, to comprehend, to use), class hour, accumulated class hour and notes, etc. Unit teaching arrangement refers to concrete arrangement toward teaching contents, teaching target, teaching activities and teaching conditions according to teaching unit in teaching schedule. It is interface and important evidence of class teaching design. Teaching contents include major contents, important points and difficult points. Teaching target includes target of knowledge, ability and quality cultivation. Teaching activities include students' independent learning activities and teaching activity contents, purpose and demand, patterns and methods and breakthrough methods of important and difficult points under the guidance of teachers. Teaching conditions refer to all software and hardware conditions as needed in this unit teaching. Teaching judge and control refers to judge and control patterns which guarantee curriculum teaching quality. It it includes diagnostic judge before class, pre-control, formative judge and process control in class and resultant judge and feedback control after class. Course examination includes course examination pattern and result assessment pattern.

\section{PROBLEMS THAT WE SHOULD NOTICE IN CURRICULUM TEACHING DESIGN}

\section{A. To clarify starting point of teaching design}

The starting point of teaching design is to promote teaching, so teachers should deeply analyze problems existing in teaching and develop activities surrounding the resolution of teaching problems. We can't design for the sake of design or design for the sake of compiling teaching design scheme.

\section{B. To value situational feature of teaching design}

Teaching design practice faces up to concrete teaching problems, so teaching design must be influenced by teachers' teaching style, students' features(especially those uncommon features) and concrete teaching environment. This demands us to have strong explanation ability toward concrete teaching environment, contents and students in design. We can't adopt general or inane design pattern or description pattern.

\section{To emphasize coherence of teaching design}

Coherence of teaching design is mainly expressed in two aspects: first, each step in teaching design should mutually depend on each other and should closely link, with each other, so we should notice coherence of the whole teaching design scheme and never lonely design each step; second, teaching activity is concrete expression of teaching strategy. Activity content and pattern should accord with teaching strategy chosen. We should never allow appearance of the phenomenon of "mistaking one for another".

\section{REFERENCES}

[1] Dong Huiyu, Modern Military School Pedagogy Teaching Material, Military Science Press, 2000

[2] Lan Jiangqiao, Case Study toward Teaching Job Judge, National Defence Industrial Press, 2008 
[3] Sato Masao, Teaching Principle,Translated by Zhong Qiquan, Beijing, Educational Science Publishing House, 2001,pp304

[4] Dai Ruihua, Curriculum Design and Teaching Strategy, Beijing Normal University Press, 2008 